\title{
The Dangers of Fat Metabolism and PUFA: Why You Don't Want to be a "Fat Burner"
}

\section{Introduction}

Low carbohydrate dieting (low carb) is popular in the paleo and ancestral diet communities. The scientific literature on the merits of this diet, however, remains contested. Examples of clinical studies showing benefits for weight loss [1] and metabolic syndrome [2] are easy to find. Likewise, studies showing negative effects, such as on exercise performance [3], also continue to be published as valid criticisms of claims made by the diet's adherents. A meta-analysis of weight loss trials suggests that low carb dieting is as or more effective than low-fat for up to one year, at which point results converge [4]. Most clinical studies do not extend to one year, let alone the decade or more that would constitute evidence of long term effects. Furthermore, even if a low carb diet does produce more rapid weight loss than other dieting regimens, it does not necessarily follow that it is healthy; several unhealthy states can cause weight loss.

These points underpin the faulty approach of using clinical studies to answer the question of whether low carb is "good" or "bad." This reduces the debate to a back and forth of dueling studies. Rather than argue a side with macro-level data, I will present a discussion on the physiology of the metabolic state achieved from a low carb diet. The discussion is in three parts, 1) acquisition of a fat-burning metabolism, 2) the long-term physiology associated with this state and 3) health implications specific to the polyunsaturated fatty acids (PUFA).

\section{1) Entering the fat-burning state}

The biochemical processes that mobilize stored and dietary fat for use as energy substrate are initiated due to a depletion of blood glucose. The key hormonal switches involved, adrenal glucocorticoids [5] and catecholamines [6], are secreted as a hypoglycemic response. These hormones are also secreted in response to fasting [7]. Unlike the reciprocity seen in the control of glucose usage by insulin [8], which is secreted as a reaction to glucose, the hormones that control fatty acid utilization are regulated by glucose, not fatty acids. This, in addition to the similarity of the hormone profile between starvation/fasting and consuming a ketogenic, very low carb diet, suggests that glucose sparing and reliance on fat as a primary energy source is the emergency, not the homeostatic, program for humans.

Another point of evidence for this view is that protein, both dietary [9] and tissue [10], is catabolized for production of glucose during hypoglycemia. This source of glucose is sufficient to prevent ketosis during carbohydrate restriction, provided a high enough protein intake [11]. For non-ketotic low carb dieting, this energy substrate production may account for much of the observed weight loss; the process of gluconeogenesis from amino acids costs approximately 33\% of the energy 
obtained in the oxidation of the resulting glucose [12]. Additionally, if the saturable urea system [13] is overwhelmed by amino acid derived ammonia, symptoms of hyperammonemia, or "rabbit starvation," follow [14]. Even at a subclinical level, greater ammonia is a burden on kidney nephrons $[15,16]$.

\section{2) The long-term physiology associated with fat burning}

Once a fat burning state is achieved, loosely defined hormonally as lower insulin and higher glucagon, cortisol and catecholamines, other changes begin to assert themselves that integrate into the overall low-level stress state. One of these changes is a depression of the respiratory quotient, as less carbon dioxide (CO2) is produced from using fat for fuel relative to using carbohydrate. Hormones of metabolic control are affected at the level of production and action.

\section{$\mathrm{CO2}$}

It is often taught that CO2 is a by-product, or even a waste product, of cellular respiration. Although it is true that $\mathrm{CO} 2$ is largely exhaled in the breath, and that inhaling pure $\mathrm{CO} 2$ is lethal, it does not follow that $\mathrm{CO} 2$ is physiologically unnecessary or without benefit. At the molecular level, CO2 is necessary for respiration through its displacement of 02 on hemoglobin [17]. At the tissue level, CO2 relaxes the smooth muscle around vessels, allowing for dilation [18]. In hypocapnic (low blood CO2) conditions, the nitric oxide system, which inhibits respiratory enzymes [19], is mobilized to ensure dilation [20].

These effects are characteristic of acute clinical hypocapnia, but subclinical capnic differences have physiological effects as well. During sleep, for example, hypercapnia increases neuronal oxygenation [21]. Additionally, the rate of Vitamin $\mathrm{K}$ dependent carboxylation reactions is determined by CO2 concentration [22]. Furthermore, abundant intra and extracellular CO2 is protective for proteins and lipids susceptible to oxidation. The relatively unreactive oxygen in CO2 transiently associates with amide bonds in proteins, which in sufficient concentrations crowds out reactive oxygen and lowers peroxidation [23,24]. Lastly, CO2 exiting the cell takes with it $\mathrm{H} 2 \mathrm{O}$ through a dynamic equilibrium with $\mathrm{H} 2 \mathrm{CO} 3$ in aqueous solution [25], lowering cellular bulk water. By removing bulk water, the stoichiometric equilibrium of ADP and ATP is pushed towards ATP. This function of CO2 production may play a large part in the insufficiently explained large increase in ATP synthesis of eukaryotic over prokaryotic enzyme systems, as the motive force of a mitochondrial proton gradient is untenable [26]. It can be concluded that within physiological levels, higher $\mathrm{CO} 2$ has benefits, and a higher ratio of carbohydrate to fat being oxidized for fuel yields greater $\mathrm{CO} 2$.

\section{Thyroid Hormone}

A molecule inextricably related to cellular $\mathrm{CO} 2$ production is thyroid hormone (triiodothyronine, T3). T3 is required to produce, among other things, the sex steroids [27] and vitamin A from beta-carotene [28]. Metabolic rate and T3 levels 
are nearly synonymous, and exert long-term control of heart rate [29] and heat production [30]. During metabolic dysregulation, or acute stress, epinephrine and norepinephrine become more involved in heart rate [31] and body temperature [32], in a similar phenomenon to energy substrate mobilization during stress described above. Despite the name of the thyroid gland, most of the body's T3 is produced in the liver by converting the prohormone tyrosine to T3. This production is dependent on liver glucose and glycogen [33] and enhanced through an insulinsuppressive action on paraventricular neuropeptide y secretion [34]. Additionally, hypoglycemia-induced glucocorticoids oppose T3 production [35]. Clinically, a calorie restricted, low carb diet causes a similar depression of T3 as starvation, which is not seen in calorie restricted carbohydrate feeding [36]. Thus a low carbohydrate diet appears to be a T3 suppressive diet.

\section{Insulin Resistance}

One of the more understood areas of macronutrient physiology is the Randle Cycle, or substrate competition between glucose and fatty acids. At the cellular level, high concentrations of malonyl-CoA from glucose metabolism inhibit the carnitine palmitoyl transferase (CPT) system that shuttles fatty acids towards beta-oxidation. Alternately, high concentrations of acetyl-CoA and citrate from beta-oxidation inhibit the pyruvate dehydrogenase complex (PDHC) that shuttles glucose metabolites towards the Citric Acid Cycle [37]. Thus, there is a tendency to continue using the fuel already in use.

This addresses the misunderstood issue of treating hyperglycemia/insulin resistance/metabolic syndrome by reducing or removing carbohydrate intake. During high-fat diet, total and oxidative glucose disposal is impaired, and pharmacological blockade of fatty acid oxidation reverses this [38]. The reduction of glycemia seen in low carb dieting is not a sign of increased insulin sensitivity, but simply a removal of the challenge. An analogy is the removal of dairy from the lactose intolerants diet; the reduction seen in their symptoms does not reflect an improvement in their ability to handle dairy. A sign of metabolic health is flexibility

of use between glucose and fat [39], but even in healthy subjects a fatty acid infusion reduces glucose disposal [40]. Fatty acid oxidation is synonymous with some degree of glucose intolerance.

Not all fatty acids participate in this effect to the same degree. Inhibition of glucose metabolism increases with chain length and degree of unsaturation of fatty acids [41]. This effect is therefore strongest with PUFA.

\section{3) Health implications specific to the polyunsaturated fatty acids (PUFA)}

\section{Breakdown Products and Metabolites}

In addition to the issues of dietary fat discussed above, PUFA carry the danger of diverse, damaging metabolites. Non-enzymatically, PUFA can be oxidized into peroxides and aldehydes that are likely a key factor in atherosclerotic plaque formation $[42,43]$, as well as damage to cellular contents, such as membrane lipids 
like mitochondria [44]. Enzymatically, lipooxygenases and peroxidases produce eicosanoids from PUFA, many of which have been shown to have inflammatory effects [45]. The prostaglandins, thromboxanes, and leukotrienes produced from n-3 PUFA are generally considered anti-inflammatory compared to those produced from n-6 PUFA [46]. This anti-inflammatory categorization based on immune activity assays is an example of another action unique to PUFA, that of enzymatic inhibition.

\section{Proteolytic Inhibition}

Most of the endocrine activity ascribed to PUFA centers around metabolites, but several purported receptors are hypothesized to accept native PUFA as ligands and alter cell function $[47,48]$. PUFA alone, for example, can lower circulating LDL [49] and, in the case of $n-3$, reduce systemic inflammation [50]. How do they accomplish these actions? Conceptually, there are two ways to reduce inflammation, one being to remove the source, as when taking an antibiotic to clear an infection, the second being to inhibit the action of immune cells, reducing markers of inflammation absent addressing the cause. Some evidence points to PUFA working via the latter mechanism.

The LDL lowering effects of PUFA could be caused by inhibition of the proteolytic cleavage of sterol regulatory element-binding protein-1 (SREBP-1) from the cytosolic matrix [51], a similar phenomenon to Tuberculosis bacilli-derived PUFA inhibition of tryptic digestion [52]. The glucuronosyltransferase enzyme, a drug clearance system in the liver, is similarly inhibited in the presence of PUFA [53]. In nature, the most abundant source of PUFA, plant seeds, lay dormant until germination is activated in part by decoupling stored PUFA from their enzymes through water driven $\mathrm{H} 2 \mathrm{O} 2$ production [55]. The other significant natural source of PUFA is cold-water fish. These fish use PUFA in order to maintain low viscosity in temperatures approaching the freezing point of water, consequently adapting very low metabolic rates [56].

Plant seeds and cold-water fish have very different metabolisms and physiological needs than mammals. The suppressive actions of PUFA may explain why one of the symptoms of so-called essential fatty acid deficiency is a $25-30 \%$ increase in the basal metabolic rate [57]. Thyroid hormone, discussed above as the master metabolic regulator, is blocked at the production [58], transport [59], and cellular action [60] steps by PUFA. If fat, in the context of mammalian systems, is a storage fuel to be used during emergencies, PUFA is an agent by which that system is slowed for preservation over the course of the emergency.

\section{Conclusion}

Liberated fatty acids in general, and PUFA in specific, slow the cellular processes of high metabolic rate organisms. Evidence for the effects on thyroid hormone, CO2, insulin action, etc. is here presented, but ultimately "good" or "bad" vis a vis low carb can only be decided through perspective. Many believe that slowing down the metabolic rate can extend life by reducing wear on the body. This perspective is 
exemplified in the caloric restriction community. Others believe that the reduction in metabolic rate during aging is a harbinger of decline to be opposed. This could be called the metabolic hypothesis. It is also argued that acute stress and even inflammation is adaptive and beneficial to long-term health. Intermittent fasting puts those ideas into practice. Again, an opposing school of thought advises to eat many small meals throughout the day to avoid the stress response of fasting and support homeostasis.

This article, and the talk it drew from, is an attempt to ground discussion in the first principles of physiology. It is an interesting aspect of the low carb debate that some of the very same phenomena, or perhaps the connotative definitions of them, are seen as good by one side and bad by the other. This shows the futility of the dueling studies approach to debate, as nearly every diet and health paradigm has literature to support it. A lens of perspective must be rigorously applied to this literature and to the claims of its proponents.

Ultimately, health is determined by outcomes rather than inputs, and an agreedupon definition is required for discussion. I suggest Dr. Michel Accad's praxeological definition of health "as the state that is present when one's physical and mental conditions allow the pursuit of one's chosen ends," as opposed to the current medical one of "body as machine" that either does or does not currently present defects. Starting from a place of clarity, and moving through evidence with precision, correct conclusions are more likely to be arrived at than through the back and forth "gotcha" of the presentation of insufficiently examined information.

\section{References}

[1] Brehm BJ, Seeley RJ, Daniels SR, D’Alessio DA. A randomized trial comparing a very low carbohydrate diet and a calorie-restricted low fat diet on body weight and cardiovascular risk factors in healthy women. J Clin Endocrinol Metab 2003;88:1617-23. doi:10.1210/jc.2002-021480.

[2] Boden G, Sargrad K, Homko C, Mozzoli M, Stein TP. Effect of a lowcarbohydrate diet on appetite, blood glucose levels, and insulin resistance in obese patients with type 2 diabetes. Ann Intern Med 2005;142:403-44.

[3] Burke LM, Ross ML, Garvican-Lewis LA, Welvaert M, Heikura IA, Forbes SG, et al. Low Carbohydrate, High Fat diet impairs exercise economy and negates the performance benefit from intensified training in elite race walkers. J Physiol 2017;Accepted A:1-61. doi:10.1113/JP273230.

[4] Nordmann AJ, Nordmann A, Briel M, Keller U, Yancy Jr. WS, Brehm BJ, et al. Effects of low-carbohydrate vs low-fat diets on weight loss and cardiovascular risk factors: a meta-analysis of randomized controlled trials. Arch Intern Med 2006;166:285-93. doi:10.1001/archinte.166.3.285.

[5] Plonk JW, Bivens CH, Feldman JM. Inhibition of Hypoglycemia-Induced Cortisol Secretion by the Serotonin Antagonist Cyproheptadine. J Clin Endocrinol Metab 1974;38:836-40.

[6] Goldfien A, Moore R, Havens LL, Boling MD, Thorn GW. Plasma Epinephrine 
and Norepinephrine Levels During Insulin-Induced Hypoglycemia in Man. J Clin Endocrinol Metab 1961;21:296-304.

[7] Samuels M, McDaniel P. Thyrotropin Levels during hydrocorticosterone infusions that mimic fasting-induced cortisol elevations: a Clinical Research Study. J Clin Endocrinol Metab 1997;82:3700-4. doi:10.1210/jcem.82.11.4376.

[8] Yeo R, Sawdon M. Hormonal control of metabolism: regulation of plasma glucose. Anaesth Intensive Care Med 2013;14:296-300. doi:10.1016/j.mpaic.2013.04.009.

[9] Stumvoll M, Meyer C, Perriello G, Kreider M, Welle S, Gerich J. Human kidney and liver gluconeogenesis: evidence for organ substrate selectivity. Am J Physiol 1998;274:E817-26.

[10] Ruderman N. Muscle amino acid metabolism and gluconeogenesis. Annu Rev Med 1975;26:245-58.

[11] Bielohuby M, Menhofer D, Kirchner H, Stoehr BJM, Muller TD, Stock P, et al. Induction of ketosis in rats fed low-carbohydrate, high-fat diets depends on the relative abundance of dietary fat and protein. Am J Physiol Endocrinol Metab 2011;300:E65-76. doi:10.1152/ajpendo.00478.2010.

[12] Bender DA. The metabolism of "surplus" amino acids. Br J Nutr 2012;108:S113-121. doi:10.1017/S0007114512002292.

[13] Rudman D, DiFulco TJ, Galambos JT, Smith IIIrd RB, Salam AA, Warren WD. Maximal rates of excretion and synthesis of urea in normal and cirrhotic subjects. J Clin Invest 1973;52:2241-9. doi:10.1172/JCI107410.

[14] Speth JD, Spielmann KA. Energy source, protein metabolism, and huntergatherer subsistence strategies. J Anthropol Archaeol 1983;2:1-31. doi:10.1016/0278-4165(83)90006-5.

[15] FITZPATRICK JM, MONSON JRT, GUNTER PA, WATKINSON LE, WICKHAM JEA. Renal Accumulation of Ammonia: The Cause of Post-lschaemic Functional Loss and the "Blue Line." Br J Urol 1982;54:608-12. doi:10.1111/j.1464410X.1982.tb13606.x.

[16] Preuss HG, Murdaugh H V. The toxic effect of ammonia on renal cortical tubule function in vitro. J Lab Clin Med 1968;71:561-72.

[17] Tyuma I. The Bohr Effect and the Haldane Effect in Human Hemoglobin. Jpn J Physiol 1984;34:205-16. doi:10.3109/00365517309082411.

[18] Kontos HA, Wei EP, Raper AJ, Patterson JL. Local mechanism of CO2 action of cat pial arterioles. Stroke 1977;8:226-9. doi:10.1161/01.STR.8.2.226.

[19] Cleeter MWJ, Cooper JM, Darley-Usmar VM, Moncada S, Schapira AH V. Reversible inhibition of cytochrome c oxidase, the terminal enzyme of the mitochondrial respiratory chain, by nitric oxide: implications for neurodegenerative diseases. FEBS Lett 1994;345:50-4.

[20] Moncada S, Palmer RMJ, Higgs AE. The Discovery of Nitric Oxide as the Endogenous Nitrovasodilator. Hypertension 1988;12:365-72.

[21] Brzecka A. Role of hypercapnia in brain oxygenation in sleep-disordered breathing. Acta Neurobiol Exp (Wars) 2007;67:197-206.

[22] Rishavy MA, Hallgren KW, Berkner KL. The vitamin K-dependent carboxylase generates gamma-carboxylated glutamates by using $\mathrm{CO} 2$ to facilitate 
glutamate deprotonation in a concerted mechanism that drives catalysis. J Biol Chem 2011;286:44821-32. doi:10.1074/jbc.M111.249177.

[23] Baev VI, Vasil'eva I V, L’vov SN, Shugaleĭ I V. The unknown physiological role of carbon dioxide. Fiziol Zhurnal Im IM Sechenova 1995;81:47-52.

[24] Boljevic S, Kogan AH, Gracev S V, Jelisejeva S V, Daniljak IG. Carbon dioxide inhibits the generation of active forms of oxygen in human and animal cells and the significance of the phenomenon in biology and medicine. Vojnosanit Pregl 1996;53:261-74.

[25] Tresguerres M, Buck J, Levin LR. Physiological carbon dioxide, bicarbonate, and pH sensing. Pflugers Arch 2010;460:953-64. doi:10.1007/s00424-0100865-6.Physiological.

[26] Ling GN. Oxidative Phosphorylation and Mitochondrial Physiology: A Critical Review of Chemiosmotic Theory, and Reinterpretation by the AssociationInduction Hypothesis. Physiol Chem Phys 1981;13:29-96.

[27] Gordon GG, Southren AL. Thyroid-Hormone Effects on Steroid-Hormone Metabolism. Bull N Y Acad Med 1977;53:241-59.

[28] Wiese CE, Mehl JW, Deuel HJ. Studies on Carotenoid Metabolism IX. Conversion of Carotene to Vitamin A in the Hypothyroid Rat. J Biol Chem 1948;175:21-8.

[29] Klein I, Ojamaa K. Thyroid hormone and the cardiovascular system. N Engl J Med 2001;344:501-9.

[30] Warner A, Mittag J. Thyroid hormone and the central control of homeostasis. J Mol Endocrinol 2012;49:29-35. doi:10.1530/JME-12-0068.

[31] Grassi G, Vailati S, Bertinieri G, Seravalle G, Stella ML, Dell'Oro R, et al. Heart rate as marker of sympathetic activity. J Hypertens 1998;16:1635-9.

[32] Jessen K. An assessment of human regulatory nonshivering thermogenesis. Acta Anaesthesiol Scand 1980;24:138-43.

[33] Balsam A, Ingbar SH. The influence of fasting, diabetes, and several pharmacological agents on the pathways of thyroxine metabolism in rat liver. J Clin Invest 1978;62:415-24. doi:10.1172/JCI109143.

[34] McCarty MF. Central insulin may up-regulate thyroid activity by suppressing neuropeptide Y release in the paraventricular nucleus. Med Hypotheses 1995;45:193-9. doi:10.1016/0306-9877(95)90068-3.

[35] Duick DS, Warren DW, Nicoloff JT, Otis CL. Effect of Single Dose Dexamethasone on the Concentration of. J Clin Endocrinol Metab 1974;39:1151-4.

[36] Spaulding SW, Chopra IJ, Sherwin RS, Lyall SS. Effect of caloric restriction and dietary composition on serum T3 and reverse T3 in man. J Clin Endocrinol Metab 1976;42:197-200. doi:10.1210/jcem-42-1-197.

[37] Randle PJ, Garland PB, Hales CN, Newsholme EA. The glucose fatty-acid cycle its role in insulin sensitivity and the metabolic disturbances of diabetes mellitus. Lancet 1963;281:785-9. doi:10.1016/S0140-6736(63)91500-9.

[38] Schrauwen P, Timmers S, Hesselink MKC. Blocking the entrance to open the gate. Diabetes 2013;62:703-5. doi:10.2337/db12-1663.

[39] Galgani JE, Moro C, Ravussin E. Metabolic flexibility and insulin resistance. Am J Physiol Endocrinol Metab 2008;295:E1009-17. 
doi:10.1152/ajpendo.90558.2008.

[40] Felley CP, Felley EM, van Melle GD, Frascarolo P, Jéquier E, Felber JP. Impairment of glucose disposal by infusion of triglycerides in humans: role of glycemia. Am J Physiol 1989;256:E747-52.

[41] Power GW, Yaqoob P, Harvey DJJ, Newsholme EAA, Calder PCC. The effect of dietary lipid manipulation on hepatic mitochondrial phospholipid fatty acid composition and carnitine palmitoyltransferase I activity. Biochem Mol Biol Int 1994;34:671-84.

[42] Steinbrecher UP, Parthasarathy S, Leake DS, Witztum JL, Steinberg D. Modification of low density lipoprotein by endothelial cells involves lipid peroxidation and degradation of low density lipoprotein phospholipids. Proc Natl Acad Sci U S A 1984;81:3883-7.

[43] Young IS, Mceneny J. Lipoprotein oxidation and atherosclerosis. Biochem Soc Trans 2001;29:358-62.

[44] Yin H, Xu L, Porter NA. Free Radical Lipid Peroxidation: Mechanisms and Analysis. Chem Rev 2011;111:5944-72. doi:10.1021/cr200084z.

[45] Ricciotti E, Fitzgerald GA. Prostaglandins and inflammation. Arterioscler Thromb Vasc Biol 2011;31:986-1000. doi:10.1161/ATVBAHA.110.207449.

[46] Wall R, Ross RP, Fitzgerald GF, Stanton C. Fatty acids from fish: The antiinflammatory potential of long-chain omega-3 fatty acids. Nutr Rev 2010;68:280-9. doi:10.1111/j.1753-4887.2010.00287.x.

[47] Georgiadi A, Kersten S. Mechanisms of Gene Regulation by Fatty Acids. Adv Nutr 2012;3:127-34. doi:10.3945/an.111.001602.factors.

[48] Grygiel-Górniak B. Peroxisome proliferator-activated receptors and their ligands: nutritional and clinical implications - a review. Nutr J 2014;13:1-10. doi:10.1186/1475-2891-13-17.

[49] Bjermo H, Iggman D, Kullberg J, Dahlman I, Johansson L, Persson L, et al. Effects of n-6 PUFAs compared with SFAs on liver fat , lipoproteins, and inflammation in abdominal obesity : a randomized controlled trial. Am J Clin Nutr 2012;95:1003-12. doi:10.3945/ajcn.111.030114.1.

[50] Calder PC. n-3 Polyunsaturated fatty acids, inflammation, and inflammatory diseases. Am J Clin Nutr 2006;83:1505S-1519S.

[51] Yoshikawa T, Shimano H, Yahagi N, Ide T, Amemiya-Kudo M, Matsuzaka T, et al. Polyunsaturated fatty acids suppress sterol regulatory element-binding protein 1c promoter activity by inhibition of liver X receptor (LXR) binding to LXR response elements. J Biol Chem 2002;277:1705-11. doi:10.1074/jbc.M105711200.

[52] Jobling JW, Petersen W. Ferment-inhibiting substances in tubercle bacilli. J Exp Med 1914;19:251-8.

[53] Rowland A, Gaganis P, Elliot DJ, Mackenzie PI, Knights KM, Miners JO. Binding of inhibitory fatty acids is responsible for the enhancement of UDPglucuronosyltransferase 2B7 activity by albumin: implications for in vitro-in vivo extrapolation. J Pharmacol Exp Ther 2007;321:137-47. doi:10.1124/jpet.106.118216.

[54] Clarke SD, Hembree J. Inhibition of Triiodothyronine 's Induction of Rat Liver Lipogenic Enzymes by Dietary Fat. J Nutr 1990;120:625-30. 
[55] Wojtyla Ł, Lechowska K, Kubala S, Garnczarska M. Different Modes of Hydrogen Peroxide Action During Seed Germination. Front Plant Sci 2016;7:66. doi:10.3389/fpls.2016.00066.

[56] Johnston IA, Dunn J. Temperature acclimation and metabolism in ectotherms with particular reference to teleost fish. Symp Soc Exp Biol 1987;41:67-93.

[57] Rafael J, Patzelt J, Schafer H, Elmadfa I. The effect of essential fatty acid deficiency on basal respiration and function of liver mitochondria in rats. J Nutr 1984;114:255-62.

[58] Chopra IJ, Huang TS, Beredo A, Solomon DH, Chua Teco GN, Mead JF. Evidence for an inhibitor of extrathyroidal conversion of thyroxine to 3,5,3'triiodothyronine in sera of patients with nonthyroidal illnesses. J Clin Endocrinol Metab 1985;60:666-72. doi:10.1210/jcem-60-4-666.

[59] Tabachnick M, Korcek L. Effect of long-chain fatty acids on the binding of thyroxine and triiodothyronine to human thyroxine-binding globulin. Biochim Biophys Acta - Gen Subj 1986;881:292-6. doi:10.1016/0304-4165(86)900164.

[60] Wiersinga WM, Chopra IJ, Chua Teco GN. Inhibition of nuclear T3 binding by fatty acids. Metabolism 1988;37:996-1002. 